\title{
Obtainment and Characterization of a Silicon alkoxides-based Coating Applied to a Substrate of Stainless Steel 316L for Use in Biomaterials
}

\author{
Marielen Longhi $^{a, c}$, Rosiana Boniatti Casagrande ${ }^{a}$,Sandra Raquel Kunst ${ }^{b}$, Venina dos Santos ${ }^{c *}$, \\ Jane Zoppas Ferreira ${ }^{a}$ \\ ${ }^{a}$ Laboratório de Corrosão, Proteção e Reciclagem de Materiais - LACOR, Universidade Federal do Rio \\ Grande do Sul, Porto Alegre, RS, Brasil \\ ${ }^{b}$ Instituto de Ciências Exatas e Tecnológicas - ICET, Universidade Feevale, Novo Hamburgo, RS, Brasil \\ 'Programa de Pós-Graduação em Engenharia de Processos e Tecnologias, Universidade de Caxias do \\ Sul, Caxias do Sul, RS, Brasil
}

Received: July 23, 2018; Revised: December 26, 2018; Accepted: February 15, 2019

\begin{abstract}
The silicon alkoxides-based coating is an alternative to control the release of cytotoxic ions through metal implants. This study evaluated the influence of the number of layers of a hybrid coating on the surface of austenitic stainless steel AISI 316L on the corrosion resistance. This coating was produced from the precursors of silicon alkoxides 3-(trimethoxysilyl)propyl methacrylate (MAP) and tetraethoxisylane (TEOS) obtained by sol-gel process, and easily applied by dip-coating. Results indicated that a single layer of coating in the substrate showed a better protection than two layers. This single layer developed by the combination of the precursors TEOS-MAP was enough to create a compact and uniform film with good adherence to AISI 316L and higher electrochemical development. A single layer of TEOS-MAP coating is more adequate as a protective coating for the AISI 361L than the sample subjected to two layers and the non-coated substrate, because this film ensures its integrity in an aggressive environment.
\end{abstract}

Keywords: Stainless steel 316L, coatings, sol-gel, corrosion.

\section{Introduction}

Austenitic stainless steels AISI 316L are widely used in several industrial applications and, due to their low level of carbon, are considered biocompatible. These materials are used in many devices, orthopedic and dentistry implants ${ }^{1-3}$. Among many advantages of AISI $316 \mathrm{~L}$ one could mention its mechanical properties, the easiness of formability and its relatively low cost, especially when compared to other metallic materials, such as titanium alloys ${ }^{4-8}$.

Although the AISI $316 \mathrm{~L}$ is considered resistant to general corrosion, it can be susceptible to pitting and interstitial corrosion depending on the environment it is inserted in ${ }^{4}$. The prolonged contact with body fluids, minerals, chlorides, amino acids and proteins in the human physiological environment, for instance, can favor the corrosion of implants made of AISI $316 \mathrm{~L}^{3}$. In this process, the release of metallic ions such as nickel $(\mathrm{Ni})$, iron $(\mathrm{Fe})$, cobalt $(\mathrm{Co})$, chrome $(\mathrm{Cr})$ and its compounds, which consists in the products of corrosion of stainless steel, can occur ${ }^{1,6}$.

In addition, these metallic ions, known as allergens, when released can accumulate inside the tissues adjacent to the implant or can be carried through the bloodstream to various parts of the body ${ }^{1,3}$. Consequently, they can cause inflammatory reactions inside the adjacent tissues and accumulation of metallic debris which can lead to necrosis and decrease of time for fixation to the bone, thus causing

*email: vsantos2@ucs.br destabilization and loosening, which are frequent causes of implant failures ${ }^{1,6,9,10}$. The direct consequence of these failures is the need for new surgeries to review or even to substitute the implants, causing discomfort and inconvenience to the patients, as well as extra unnecessary costs ${ }^{9}$.

In view of minimizing these negative effects, coatings applied to the surface of AISI 316L implants become an alternative to avoid the direct contact of the metal to body fluids and improve the biocompatibility and corrosion resistance ${ }^{1}$. Among the coatings used, the ones obtained by the sol-gel method present advantages in relation to other coating techniques, such as decreased sintering temperature, capability of coating complex forms, increased homogeneity, high control of composition, microstructure and thickness of obtained films ${ }^{1,6,11}$. Furthermore, these coatings present a relatively low cost and require a simple equipment to operate $^{1,11}$.

Therefore, the use of an organic-inorganic hybrid coating based on alkoxide precursors, particularly with silicon compounds, for surface protection of the metal substrate is an excellent ecologically friendly alternative, which is not rejected by the human body and does not degrade in body fluids. It also favors the ideal cell growth for the recovery and biocompatibility of osseointegration ${ }^{11,12}$.

A number of authors, when analyzing films deposited on 316L stainless steel, did not observe alterations induced by surface corrosion after three weeks of immersion in corrosive solution. The hybrid coating prepared through a MAP/TEOS 
ratio acted as an efficient physical barrier, increasing the total impedance modulus and reducing current densities by two orders of magnitude in comparison to uncoated samples ${ }^{11-14}$.

By applying the sol-gel process it is possible to obtain a hybrid protection with silicon alkoxides-based coatings. These coatings have been highlighted because of their barrier properties and absence of toxicity. Its efficiency is due to the combination of inorganic and organic properties in the same film ${ }^{12-14}$.

For the deposition of the coating in the surface of metallic substrates, the dip-coating method has been widely used. This method provides a controlled speed for immersion and removal of the sample from the sol, allowing the control of the thickness of the film ${ }^{12,15}$. This is a simple and cheap technique that allows all sides of a sample to be coated simultaneously.

Although it has already been mentioned that silanes are efficient for the protection of metallic substrates against corrosion, the efficiency of the protection given by the coating layer depends on some parameters, such as structure and silane concentration ${ }^{16}$, processing conditions, solution $\mathrm{pH}$, time of hydrolysis ${ }^{17}$, retention time of the solution in contact with the substrate, as well as the number of applications of the film and the curing temperature ${ }^{16,18}$.

The present study approached the topic in association with biomaterials and evaluated the corrosion capacity of films on $316 \mathrm{~L}$ stainless steel. The aim was to improve their anticorrosive characteristics and also their biocompatibility with the use of hybrid coatings based on alkoxy silane precursors.

The objective of this study was to evaluate the influence of the number of layers of hybrid coatings in the surface of the austenitic stainless steel AISI 316L substrates considering corrosion resistance. The studied coatings are hybrid films produced from precursors of silicon alkoxides 3-(trimethoxysilyl) propyl methacrylate (MAP) and tetraethoxisylane (TEOS) obtained by the sol-gel process, and applied in the AISI 316L by dip-coating.

\section{Materials and Methods}

\subsection{Materials}

Stainless steel AISI 316L (provided by Michelon Máquinas e Equipamentos, Ltda, Brazil) in the form of $20 \times 20 \mathrm{~mm}^{2}$ sheets with $2 \mathrm{~mm}$ of thickness was used as substrate. The chemical composition of the steel was confirmed by the method of flame atomic emission spectroscopy: $\mathrm{C} 0.03 \% \max$, Mn 2\% max, Si 1\% max, P 0.045\% max, S 0.03\% max, Ni 10-14\%, Cr 16-18\%, Mo 2-3\%, balance Fe. Before receiving the hybrid film, all samples were sanded with silicon carbide sandpaper of different grids (\#320, \#600, \#1000 and \#1200) for leveling their surfaces. After this process, the samples were degreased with an alkaline detergent and rinsed with distilled water. Subsequently, in order to improve the adhesion of the coating to the substrate, the samples were submitted to an alkaline pre-treatment with sodium hydroxide $(\mathrm{NaOH}$ $0.01 \mathrm{~mol} \cdot \mathrm{L}^{-1}$ ) for $3 \mathrm{~min}$ at $20^{\circ} \mathrm{C}^{13,19}$.

\subsection{Development and application of coatings}

Coatings used in this study were obtained from hydrolysis reactions of the silicon alkoxide precursor tetraethoxisylane (TEOS, 96\%, Sigma-Aldrich) and 3-(Trimethoxysilyl) propyl methacrylate (MAP, 96\%, Sigma-Aldrich ) in ethanol $\left(\mathrm{C}_{2} \mathrm{H}_{6} \mathrm{O}, 99.5 \%\right.$, Anidrol $)$ and distilled water in the following proportions: TEOS $(10 \% \mathrm{v} / \mathrm{v})$; MAP $(15 \% \mathrm{v} / \mathrm{v})$; water $(15 \% \mathrm{v} / \mathrm{v})$; ethanol $(60 \% \mathrm{v} / \mathrm{v})^{12,20,21}$. The hybrid film was obtained by the sol-gel method and the $\mathrm{pH}$ values were adjusted with acetic acid $\left(0.1 \mathrm{~mol} \cdot \mathrm{L}^{-1}\right)$ around 4 . Child and Van Ooij ${ }^{16}$ recommended the use of acetic acid to reduce the $\mathrm{pH}$ of the hybrid solution as it evaporates rapidly in the coated surface ${ }^{13}$. Subsequently, the sol hydrolysis process was conducted for a period of $24 \mathrm{~h}$ at $20^{\circ} \mathrm{C}{ }^{22}$.

The samples were divided into two groups: a sample group was subjected to one superficial application of coating (named 316L_1), and the other sample group was subjected to two superficial applications of hybrid coating (named $316 \mathrm{~L} \_2$ ). The samples were identified according to Table 1.

Group 316L_1 received one application of sol in the metallic surface by dip-coating, with a rate of immersion and removal of $10 \mathrm{~cm} \cdot \mathrm{min}^{-1}$ and a permanence time of $5 \mathrm{~min}^{23}$. After the sol application, the samples remained exposed to air for $20 \mathrm{~min}$ at room temperature to promote evaporation of the solvents and to begin condensation of the coating onto the substrate process. The obtained film was cured in an oven for $1 \mathrm{~h}$ at $90^{\circ} \mathrm{C}{ }^{12,13}$.

In the $316 \mathrm{~L} \_2$ group the samples were previously cured for $1 \mathrm{~h}$ at $90^{\circ} \mathrm{C}$, like group 1 , and received another hybrid layer by dip-coating with a rate of immersion and removal of $10 \mathrm{~cm} \cdot \mathrm{min}^{-1}$ and a permanence time of $5 \mathrm{~min}$. After that, samples were conducted to the oven to be cured at $90^{\circ} \mathrm{C}$ for $1 \mathrm{~h}$. Figure 1 shows the process flowchart.

\subsection{Coating characterization}

A Tescan Mira3 field emission scanning electron microscope (FEG-SEM) was used to evaluate the morphology of the films. The samples were observed from a top view to identify the initial surface morphology after the electrochemical impedance test. Additionally, the samples were observed in cross section to evaluate the thickness of the films.

Table 1. Description of studied samples.

\begin{tabular}{lc}
\hline Sample & Description \\
\hline $316 \mathrm{~L}$ & AISI 316L sanded stainless steel \\
$316 \mathrm{~L} \_1$ & 316 L sanded stainless steel with a single TEOS- \\
& MAP coating application \\
316L_2 & 316 L sanded stainless steel with two TEOS-MAP \\
coating application
\end{tabular}




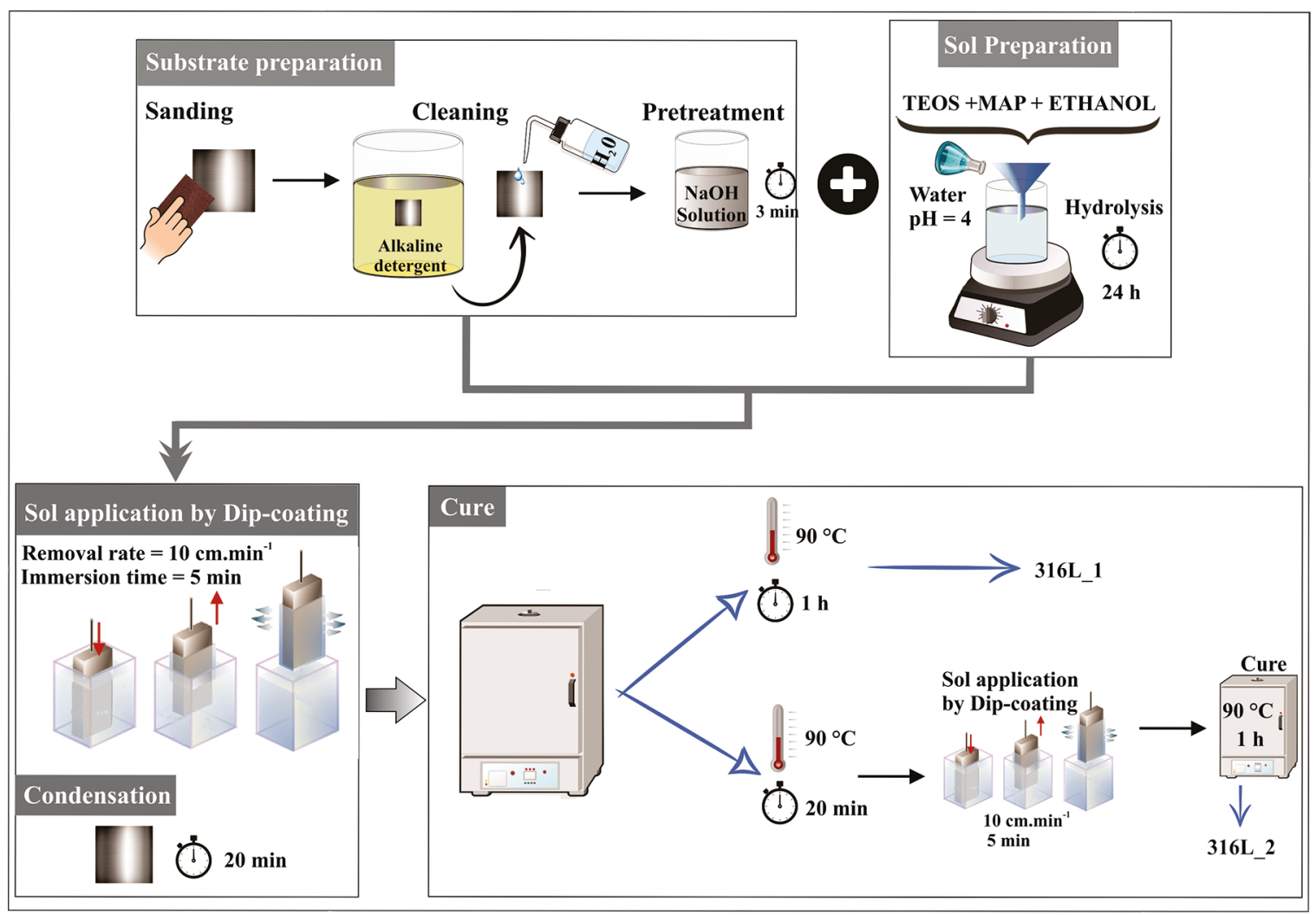

Figure 1. Flowchart with experimental parameters for sol synthesis and procedures for coating deposition in the substrate.

Elemental mapping of the films was performed by energy dispersive spectroscopy (EDS), using Oxford Instruments $\mathrm{X}$-Maxd equipment.

An adhesion test (crosshatch and tape pull test) was performed in accordance with ASTM D-3359 standards. It was performed over 7 vertical and 7 horizontal lines, forming squares of $1 \mathrm{~mm} \times 1 \mathrm{~mm}$. After $3 \mathrm{~min}$, the tape was removed in a direction parallel to the substrate.

The wettability of the samples was evaluated through contact angle measurements by the sessile drop method, using a device developed by the Research Laboratory in Chemistry of Materials (University of Caxias do Sul). The contact angle was determined using a software application for image analysis and the measurements were performed by the software Surftens 3.0.

Atomic force microscopy (AFM) analysis was performed with a Shimadzu SPM-9700, operating in contact mode, with SiN tips and a vertical scan capability of $8 \mu \mathrm{m}$ and scanning area of $10 \mu \mathrm{m} \times 10 \mu \mathrm{m}$. The evaluation of the surface roughness by AFM was carried out through Ra measurements of Ra (arithmetical mean deviation of the profiles).

The electrochemical tests were conducted so as to evaluate the barrier and protective effect of the studied films. Corrosion performance of the coatings was evaluated by using open circuit potential (OCP) monitoring, polarization curves and electrochemical impedance spectroscopy (EIS) in a simulated body fluid (SBF) electrolyte. SBF was prepared with the following chemical composition: $\mathrm{NaCl}(8.053$ $\left.\mathrm{g} \cdot \mathrm{L}^{-1}\right), \mathrm{KCl}\left(0.224 \mathrm{~g} \cdot \mathrm{L}^{-1}\right), \mathrm{CaCl}_{2}\left(0.278 \mathrm{~g} \cdot \mathrm{L}^{-1}\right), \mathrm{MgCl}_{2} \cdot 6 \mathrm{H}_{2} \mathrm{O}$, $\left(0.305 \mathrm{~g} \cdot \mathrm{L}^{-1}\right), \mathrm{K}_{2} \mathrm{HPO}_{4}\left(0.174 \mathrm{~g} \cdot \mathrm{L}^{-1}\right), \mathrm{NaHCO}_{3}\left(0.353 \mathrm{~g} \cdot \mathrm{L}^{-1}\right)$, $\left(\mathrm{CH}_{2} \mathrm{OH}\right)_{3} \mathrm{CNH}_{2}\left(6.057 \mathrm{~g} \cdot \mathrm{L}^{-1}\right)^{23}$. Concentrated hydrochloric acid $(\mathrm{HCl})$ was added to adjust the $\mathrm{pH}$ to $7.25 \pm 0.05$. The tests were performed with an Iviumstat potentiostat, from Ivium Technologies, assisted by the software Iviumsoft. A three-electrode cell was used; the samples as working electrode, the saturated calomel electrode (SCE) as reference electrode and platinum as auxiliary electrode. The working electrode area was $0.7 \mathrm{~cm}^{2}$ and these analyses were performed in triplicate.

The OCP was monitored during the first hour of immersion in the electrolyte before the potentiostatic polarization test. The potentiostatic polarization test was performed with a scan range of $-200 \mathrm{mV}$ below and $600 \mathrm{mV}$ above the OCP, with a scan rate of $1 \mathrm{mV} \cdot \mathrm{s}^{-1}$.

The EIS measurements were performed at the open circuit potential (after $1 \mathrm{~h}$ of immersion). The amplitude of the EIS perturbation signal was a sinusoidal $5 \mathrm{mV}$ perturbation, and the frequency ranged from $100 \mathrm{kHz}$ to $10 \mathrm{~Hz}$ with 10 points per frequency decade. The working electrode area was $0.7 \mathrm{~cm}^{2}$. For the EIS measurements, the samples were monitored for $120 \mathrm{~h}$. The amplitude of the EIS perturbation signal was a sinusoidal $10 \mathrm{mV}$ (rms) perturbation, and the frequency ranged from $100 \mathrm{kHz}$ to $10 \mathrm{~Hz}$ with 10 points per frequency decade. 


\section{Results and discussion}

Figure 2 shows the top micrographs obtained through FEG-SEM for the substrate AISI 316L (Figure 2-a), substrate with application of one layer Figure 2(b) and two layers of hybrid coating TEOS-MAP Figure 2(c), and the EDS mapping for each sample, respectively.

Figure 2(a) presents the substrate with a uniform metallic surface, with the presence of small micropores, possibly originated from the sanding process. The micrograph of the surface with application of one layer of TEOS-MAP hybrid coating (Figure 2-b) shows a regular, uniform coverage with no apparent cracks. Figure 2(c) shows the micrograph of the surface with application of two coating layers. A heterogenous morphology can be observed, with the formation of occasional accumulations that might have occurred during the condensation reaction of the film due to the precipitation of clusters with higher concentration of silicon ( $\mathrm{Si}$ ). According to Beltrami et al. (2016) ${ }^{24}$, the quantity of these accumulations is crucial for the corrosion resistance of the film. They will probably form the defects of the layer through which the electrolyte will permeate. The EDS mapping shows the presence of silane and carbon in greater quantity, which proves the presence of silicon clusters.

The behavior of the sample 316L_1 (Figure 2-b) in relation to the supposed superior adhesion might be associated to hydrogen bonds responsible for the strong substrate-coating bond due to the alkaline degrease performed. Research conducted by Deflorian et al. (2006) ${ }^{25}$, suggests that by using the alkaline pretreatment in metals provides the removal of superficial impurities, besides endowing the surface with hydroxyl, which consequently favors the formation of metalsiloxane bonds, generating a better anchorage in the interface.

Figure 3(a) and 3(b) present the micrographs with EDS mapping after the mechanical adhesion test for the substrate $316 \mathrm{~L}$ with application of hybrid coating in one and two layers, respectively. An area where the coatings were removed by the adhesion test can be observed, in both samples, highlighting the exposed substrate. The EDS mapping of this substrate shows the presence of the element iron $(\mathrm{Fe})$, the main component of the stainless steel.

Through EDS mapping it was also possible to notice that after the adhesion test the samples 316L_1 (Figure 3-a) and 316L_2 (Figure 3-b) showed a small displacing of the coating (adjacent to the incision). However, in both samples, in the trail region, the coatings remained well-adhered to the substrate. This fact was confirmed by the intensity of signal of the silicon ( $\mathrm{Si}$ ) element (blue coloring). Considering the EDS mapping and the difference of coloration in the identification of the chemical elements present, the trail where the silane film was extracted from the stiletto cut with stiletto is visible through the iron mapping. When the mapped element is iron, it is only possible to visualize it in the path where the film was removed, in the other areas of the substrate no iron is found because the silicon-based film covers the substrate. With the Si mapping it is possible to observe the presence of film on the substrate surface except on the stiletto track where the film was removed by the adhesion test.

In order to carefully evaluate the adherence test analyzed by the technician of FEG-SEM, regions close to the incision of the samples with one (Figure 3-a) and two (Figure 3-b) applications were analyzed. No expressive difference between the behavior of the different coatings tested was observed. Both adhered to the substrate $316 \mathrm{~L}$ after the adherence test. It was possible to notice that the coating pulled out only in the region of the incision, without causing damages to the rest of the film. This result indicates that the TEOS-MAP coating presented strong adherence forces (interaction between the film and surface of the substrate) and strong cohesive forces (intermolecular interaction of the film) ${ }^{12}$.

Figure 4 presents the micrographs of the transversal section of the studied samples. Samples 316L_1 and 316L_2

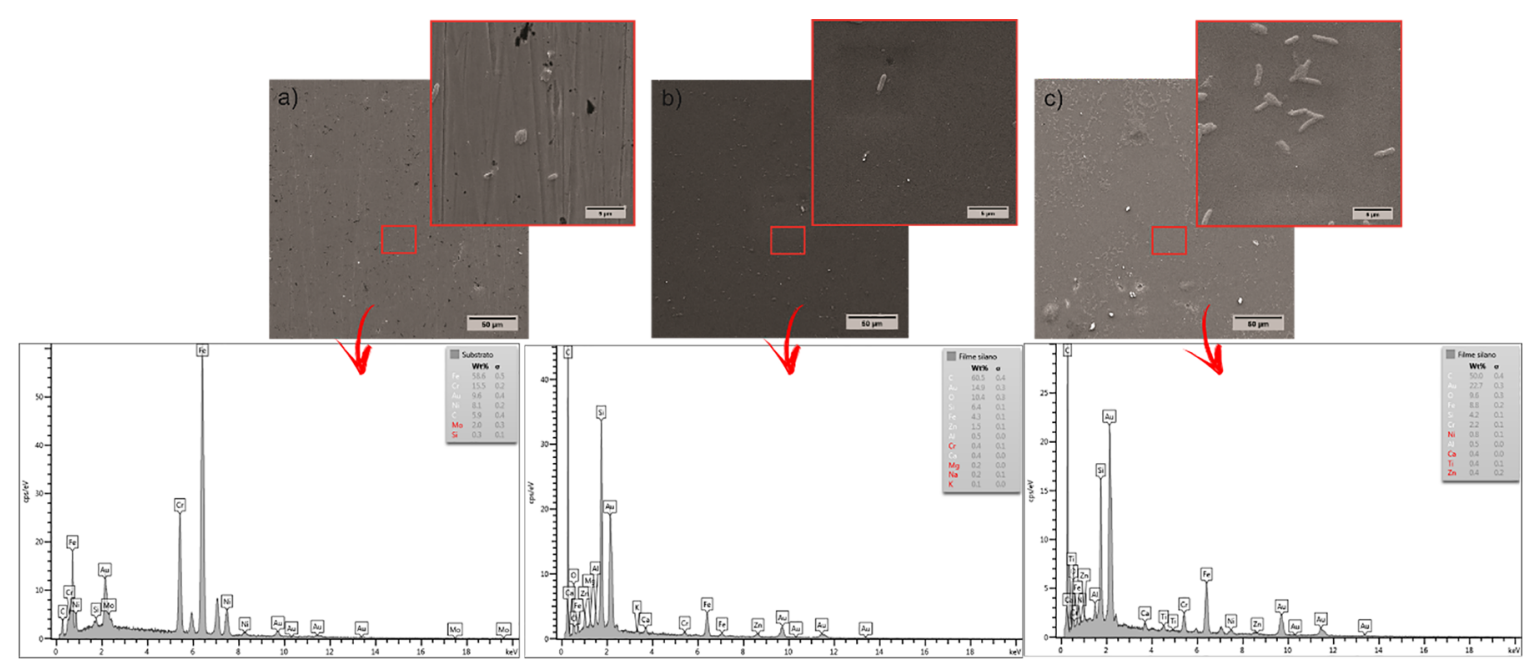

Figure 2. Top micrographs obtained through FEG-SEM for: (a) 316L, (b) 316L_1 e (c) 316L_2. Original magnification of 1000x and 10.000x. 


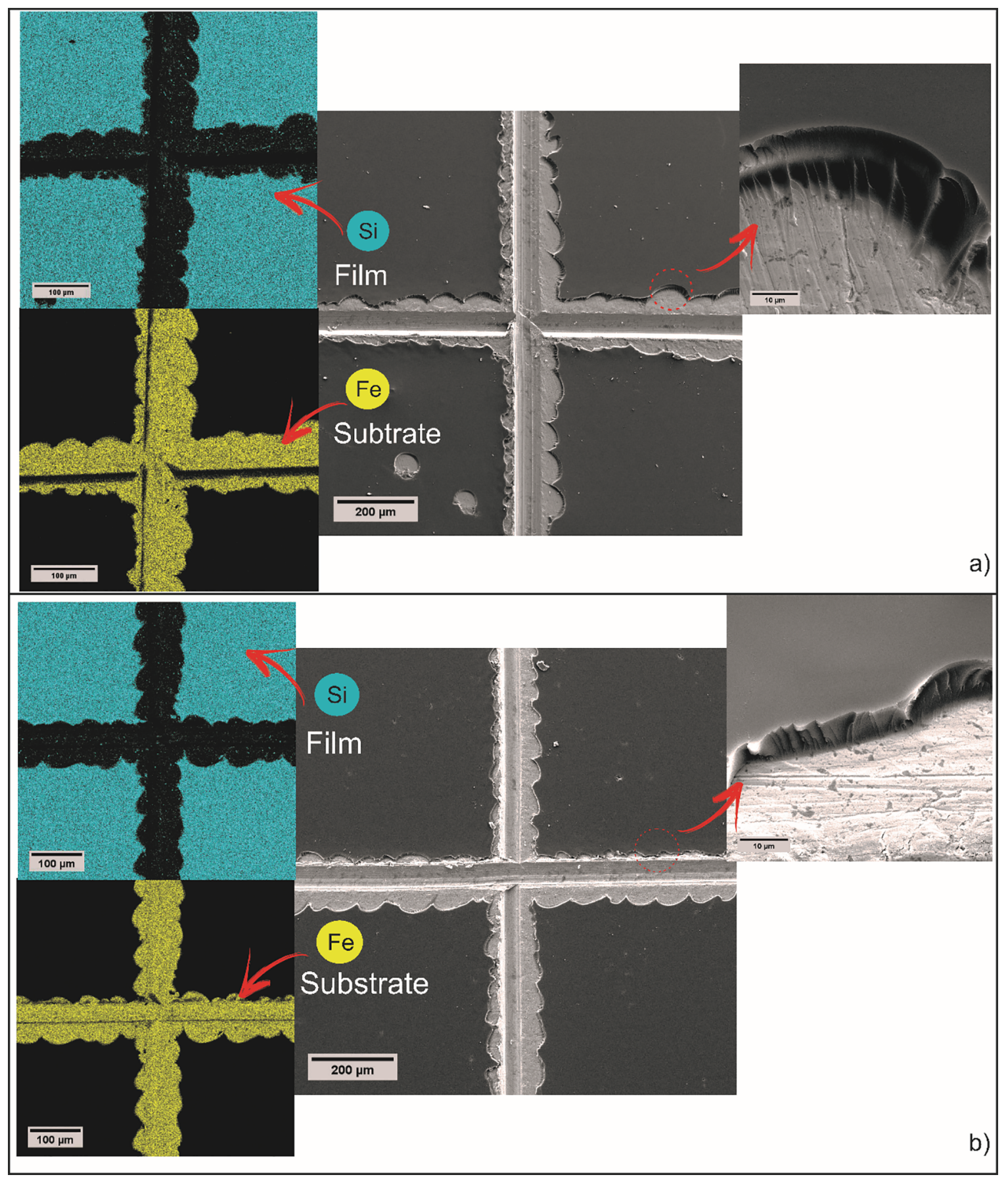

Figure 3. Top micrograph obtained through FEG-SEM and EDS mapping conducted after the adherence test in the samples: (a) 316L_1 and (b) $316 \mathrm{~L} 2$.

presented regular and visually well-adhered coatings to the substrate. The average thickness of the TEOS-MAP coating in the sample $316 \mathrm{~L} \_1$ is $7,5 \mu \mathrm{m}( \pm 0,25 \mu \mathrm{m})$ and $6,3 \mu \mathrm{m}( \pm 0,27 \mu \mathrm{m})$ in the $316 \mathrm{~L} 2$ sample.

Beltrami et al. (2016) ${ }^{24}$ affirms in their study with precursors of TEOS and MAP that the thickness of a film layer composed of alkoxide precursors depends on the structure, chemical composition and the nature of the precursor. According to the authors, the bis-silane (like MAP) lead to the formation of thicker and more homogeneous layers, besides having high capacity in the formation of $\mathrm{Me}-\mathrm{O}-\mathrm{Si}$ bonds $(\mathrm{Me}=$ metal). When proposing the reaction mechanism between TEOS-MAP, the authors highlighted that the addition of MAP to the monosilane TEOS makes the structure of the formed layer more compact due to the polymerization of the acrylate groups and their reticulation with the silicon network. 


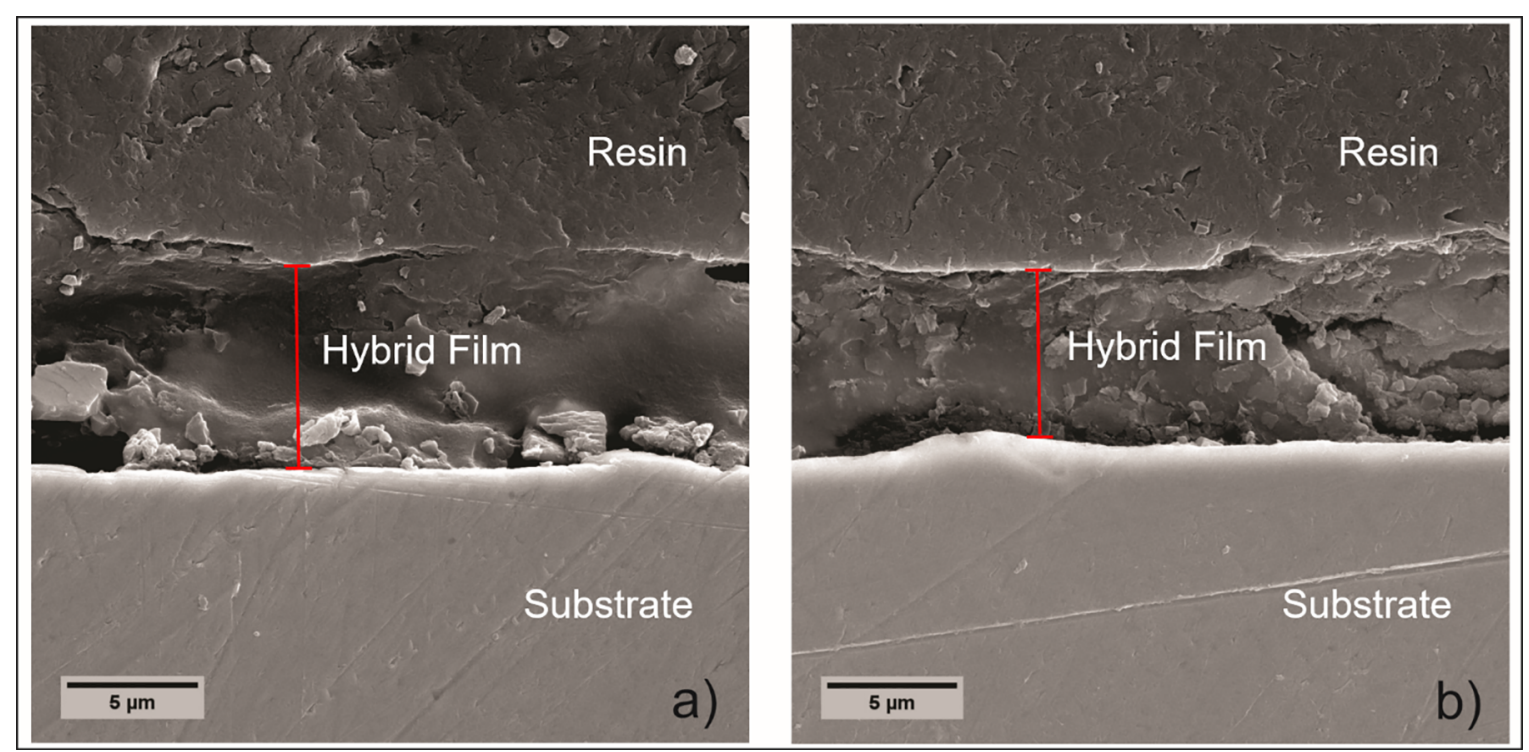

Figure 4. FEG-SEM image of the transversal section of the studied samples: (a) 316L_1 and (b) 316L_2.

Sample 316L_2 (Figure 4-b) was expected to present a higher thickness in relation to the sample 316L_1 (Figure 4-a). However, the thickness of the layer was lower. Hypothetically, a second application of a film may remove part of the first application.

According to Kunst et al. (2014) ${ }^{26}$, due to the excess of heat in the process of cure the number of reactions of silane reticulation increases, thus reducing its reactivity. This loss of reactivity is caused by the conversion of the silane groups in siloxanes. As a result, the film becomes dense and the reactions with subsequent layers become more difficult. This factor corroborated the result of the layer thickness measurement in the sample 316L_2, since it was not possible to identify a different between the layers in the transversal cut image (Figure 4-b). On the other hand, it is possible to notice a dense film similar to the sample $316 \mathrm{~L} \_1$, which refers to only one application.

Table 2 presents the mean values of contact angle obtained through the sessile drop method in the samples. From the results, it is possible to perceive that the samples have a hydrophilic surface, with a contact angle lower than $90^{\circ}$. No expressive difference between the values was observed when comparing the results of the angles of the samples with one $\left(72^{\circ}\right)$ or two $\left(71^{\circ}\right)$ applications of the hybrid coating, although both presented more hydrophilic surfaces in relation to the stainless steel sample $\left(83^{\circ}\right)$ without coating.

Table 2. Results of contact angle of the surface obtained through wettability.

\begin{tabular}{lc}
\hline Sample & Contact Angle $\left(^{\circ}\right)$ \\
\hline $316 \mathrm{~L}$ & $83 \pm 2$ \\
$316 \mathrm{~L} \_1$ & $72 \pm 1$ \\
$316 \mathrm{~L} \_2$ & $71 \pm 1$ \\
\hline
\end{tabular}

The topography of the samples was conducted based on the results of the AFM analysis (Figure 5 and Table 3 ).

The substrate 316L (Figure 5-a) has a more irregular and rough surface than the samples with one (Figure 5-b) and two (Figure 5-c) layers of coating. Through the images it is possible to observe that the coated samples presented a uniform coverage of the surface, which reduced the superficial roughness in comparison to the substrate.

Samples 316L_1 and 316L_2 present mean values of surface roughness $(\mathrm{Ra})$ lower than the observed for the sample $316 \mathrm{~L}$ as shown in Table 3. This result indicates that the coatings promoted a leveling effect in the surface of the metal.

In general, surfaces with higher roughness values have a hydrophobic character. The surface roughness results of the samples through AFM support the contact angle values obtained on the sample surfaces, which is related to the intensity of the surface energy and consequently its hydrophobicity.

The images for FEG-SEM (Figure 2-b) of the 316L_1 sample validate the images from AFM presented in Figure 5(b), where it is possible to observe in both images a surface with homogenous coverage. This behavior can also be seen for the 316L_2 sample, where the heterogeneous morphology with the formation of occasional accumulations presented in FEG-SEM (Figure 2-c) can be seen in the topography of Figure 5-c.

Beltrami et al. (2017) ${ }^{12}$ observed in his study that the coating TEOS-MAP promoted leveling, decreasing the roughness of the substrate and confirming the filing of the existing spaces in the surface through coating.

In the analysis of the OCP curves (Figure 6-a) obtained for both studied samples 316L_1 and 316L_2, it can be noticed that both present similar potential values around zero volt, a 


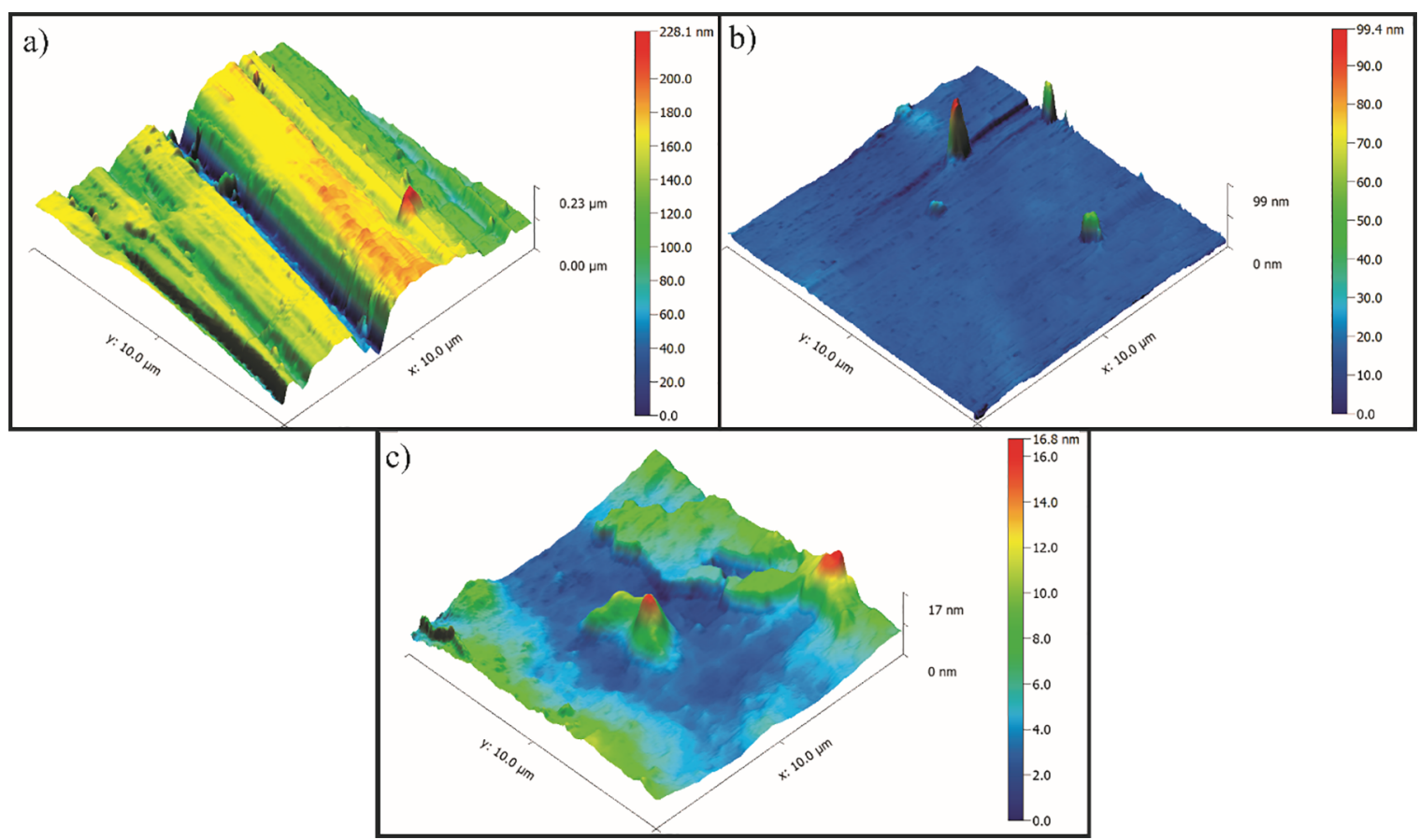

Figure 5. 3D images obtained through AFM of the surface of the studied samples: (a) 316L; (b) 316L_1 and (c) 316L_2.

Table 3. Mean roughness values obtained through AFM analysis.

\begin{tabular}{lc}
\hline Sample & Surfaces roughness Ra (nm) \\
\hline $316 \mathrm{~L}$ & $6.0 \pm 3.0$ \\
$316 \mathrm{~L} \_1$ & $0.22 \pm 0.08$ \\
316L_2 & $0.24 \pm 0.24$ \\
\hline
\end{tabular}

lower potential in comparison to stainless steel $316 \mathrm{~L}$, which was higher than $0,1 \mathrm{~V}$, demonstrating a light displacement in direction to less active potentials. This behavior was expected since the resistance to corrosion of stainless steel is provided by the formation of a passive adherent oxide film, providing the material certain stability in relation to the corrosive activity ${ }^{27}$. In general, when a metal, mainly those that become passive, is immersed in corrosive solutions the potential of corrosion is initially maintained in elevated values due to the fine layer of oxide. This potential drops to lower values after a period of time, fact which is attributed to the dissolution of the oxide layer through the process of reductive dissolution ${ }^{28}$. Austenitic stainless steel owe their resistance to corrosion to the spontaneous formation of a superficial protective layer of chrome oxide which acts as a barrier, suppressing the process of corrosion and maintaining the release of ions in lower levels ${ }^{29}$.

It is also observed in Figure 6(a) that all the studied samples present potentials with practically constant behavior over time, which is proved by the almost non-existent presence of oscillations, rapidly reaching stability. Except for one decrease in potential, after 200 seconds of immersion, for the surface of the sample $316 \mathrm{~L} \_2$, which although small (approximately $0,05 \mathrm{~V}$ ) suggests the permeability of the electrolyte SBF through the hybrid coating, thus allowing the material to be susceptible to corrosion.

When comparing the coated substrates (Figure 6-a), the $316 \mathrm{~L} \_1$ sample presented better result in the OCP condition, indicating a greater barrier effect between the steel 316L and the electrolyte, possibly due to the presence of a more compact layer without fissures as seen in the FEG-SEM images (Figure 2-b). Thus, over the immersion period, the ions of the SBF solution were not able to permeate in the coating due to its high reticulation density ${ }^{30}$.

In the polarization curves (Figure 6-b) it is possible to observe that all the samples presented, in general, a passive behavior in the tested mean. The substrate $316 \mathrm{~L}$ and the sample 316L_2 presented current density of corrosion of the same order of magnitude $\left(10^{-7} \mathrm{~A} \cdot \mathrm{cm}^{-2}\right)$. It was also noted that sample $316 \mathrm{~L} \_2$ acquired a less noble behavior (value of corrosion potential more negative from $-3,4 \mathrm{mV}$ to $-191,9$ $\mathrm{mV}$ ) and current density of corrosion a little inferior when compared to the substrate. This fact possibly occurs due to the presence of a fine layer of oxide in the surface of the metal substrate without coating, which maintain the stability of the material until the dissolution of the oxide by mean ${ }^{30,31}$.

The potential of the sample 316L_1 (Figure 6-b) presents very similar nobility with potential subtly more active $(-12,1$ $\mathrm{mV}$ ) than the substrate. However, the current corrosion density decreased up to two orders of magnitude $\left(10^{-9} \mathrm{~A} \cdot \mathrm{cm}^{-2}\right)$. This characteristic can be associated to a thick coating that prevents a more efficient passage and dissolution of aggressive ions present in the electrolyte favoring a more physical, protective barrier. These results confirm the protective effect of the film, 


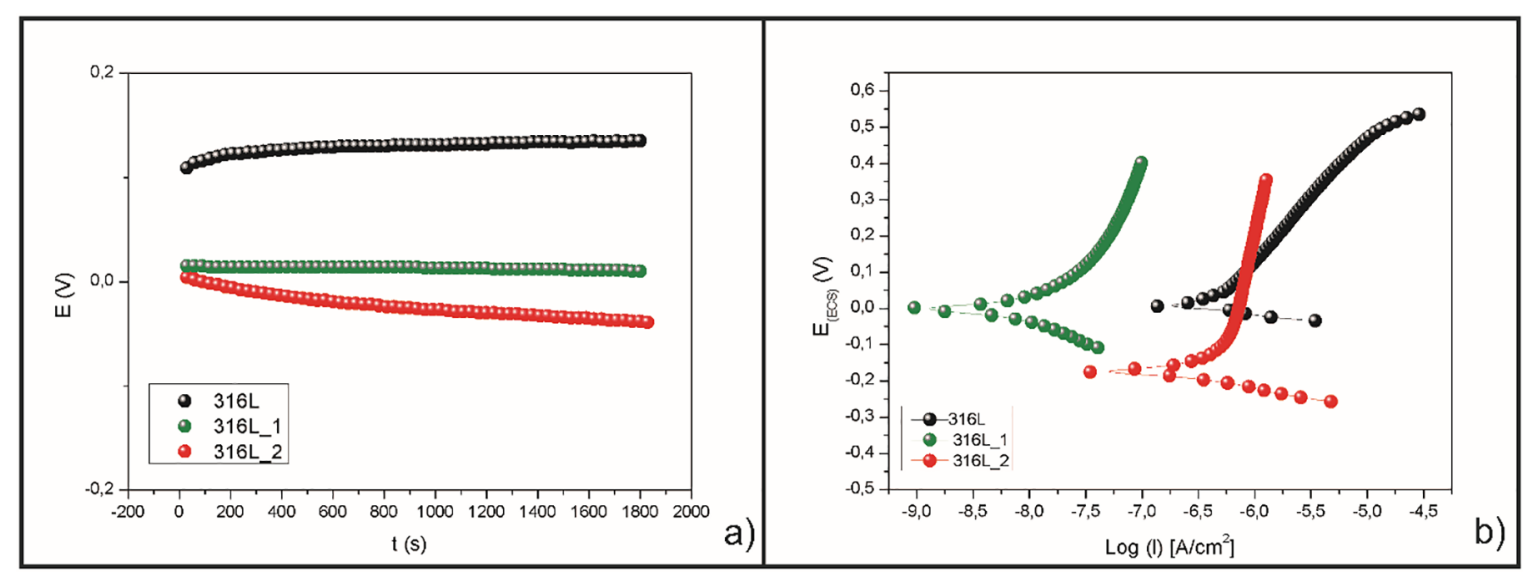

Figure 6. (a) OCP monitoring and (b) polarization curves for the studied samples in SBF solution.

indicating a good reticulation of the coating. Beltrami et al., (2017) ${ }^{12}$ also observed the protective behavior of hybrid films based on MAP and TEOS, in which samples promoted an increase in the corrosion potential value and promoted a decrease in the corrosion current density. Hosseinalipour et al. (2010) ${ }^{32}$ also obtained similar results for the sample 316L SS coated in different molar proportions of TMSM: TEOS. The coated samples presented lower current densities in comparison to the non-coated steel. The author associated this fact to the acting of the hybrid coatings as a barrier against electrochemical processes, preventing the contact between the electrolyte and the steel substrate.

The evolution of the electrochemical behavior in SBF solution was followed by Electrochemical Impedance Spectroscopy (EIS). The Bode plots for 24, 72 and 120 hours of immersion are presented in Figure 7.

The Bode plots (Figure 7) obtained through the impedance test show that the impedance module values are higher for the samples 316L_1 and 316L_2 than for the substrate $316 \mathrm{~L}$. Therefore, the protective nature of the proposed coating is highlighted, especially for the sample with one application of hybrid coating (316L_1) which presented a high phase angle above $85^{\circ}$.

For the metallic substrate analyzed (316L), shown in Figure 7, only one phenomena of low to medium frequency, which reflects the change in electrical conductivity of the passive oxide, formed over the surface during the exposure in corrosive mean, possibly related to the effect of load transfer. This response of the oxide in lower frequencies also evidences its thermodynamic instability, which justifies a lower impedance module of the substrate when compared to the coated samples $\left(316 \mathrm{~L} \_1\right.$ and $\left.316 \mathrm{~L} \_2\right)$ denoting the temporary protection provided by the oxide.

The phase angle for the stainless steel $316 \mathrm{~L}$ reached a value around $80^{\circ}$ and the variation of the impedance module with the frequency was basically linear (in the logarithmic scale). This behavior is similar to the one of an ideal capacitor, until it reached a constant value from higher frequencies, a purely resistive behavior that can be attributed to the ohmic resistance of the SBF solution.

Considering the resistance results, the sample with better anticorrosive character was $316 \mathrm{~L} \_1$. This is an expected behaviour, as this sample presents the best values in polarization curves (Figure 6). Hence, the results highlight the importance that the adequate hybrid formulation of MAP/ TEOS, the elaboration of the sol-gel process, the parameters for the dip-coating application as well as the mechanical/ chemical pretreatments employed over the stainless steel had in the formation of a uniform coating with higher adherence to the substrate. These aspects could be noticed in the MEV (Figure 3-a) and AFM (Figures 5-b) images, thus improving the performance of the barrier film against corrosion.

With 24 hours of immersion (Figure 7) a high frequency phenomenon associated to the barrier effect of the coating in the 316L_1 sample can be distinguished, explained by the presentation of a superior thickness layer in relation to the sample 316L_2, as observed in the micrograph of the transversal section in Figure 4(a). The fact that this sample does not present any phenomena at lower frequencies highlights even more its high performance against corrosion ${ }^{32}$.

However, the 316L_2 sample presented one lower frequency phenomena which suggests the possible presence of a corrosion product, indicating a sample with lower resistance and an inferior electrochemical behavior, as observed in the measures of OCP (Figure 6). The heterogenous morphology of the coating observed in the micrograph of Figure 2-c reinforces the behavior presented by this sample, compromising its the barrier protection mechanisms.

After 96 hours of immersion, the high frequency phenomena remains present in the coated samples $\left(316 \mathrm{~L} \_1\right.$ and $\left.316 \mathrm{~L} \_2\right)$, presenting a slight dislocation from a little over $4 \mathrm{~Hz}$ to a little below $4 \mathrm{~Hz}$. This is a consequence of the diffusion of the electrolyte through the superficial organic network of the coatings, which refers to the part of the non-hydrolyzed organic radical of the alkoxide precursor TEOS that is over the surface once it does not adhere to the metal or to other silanol groups, according to Kunst et al. (2013) ${ }^{22}$. 


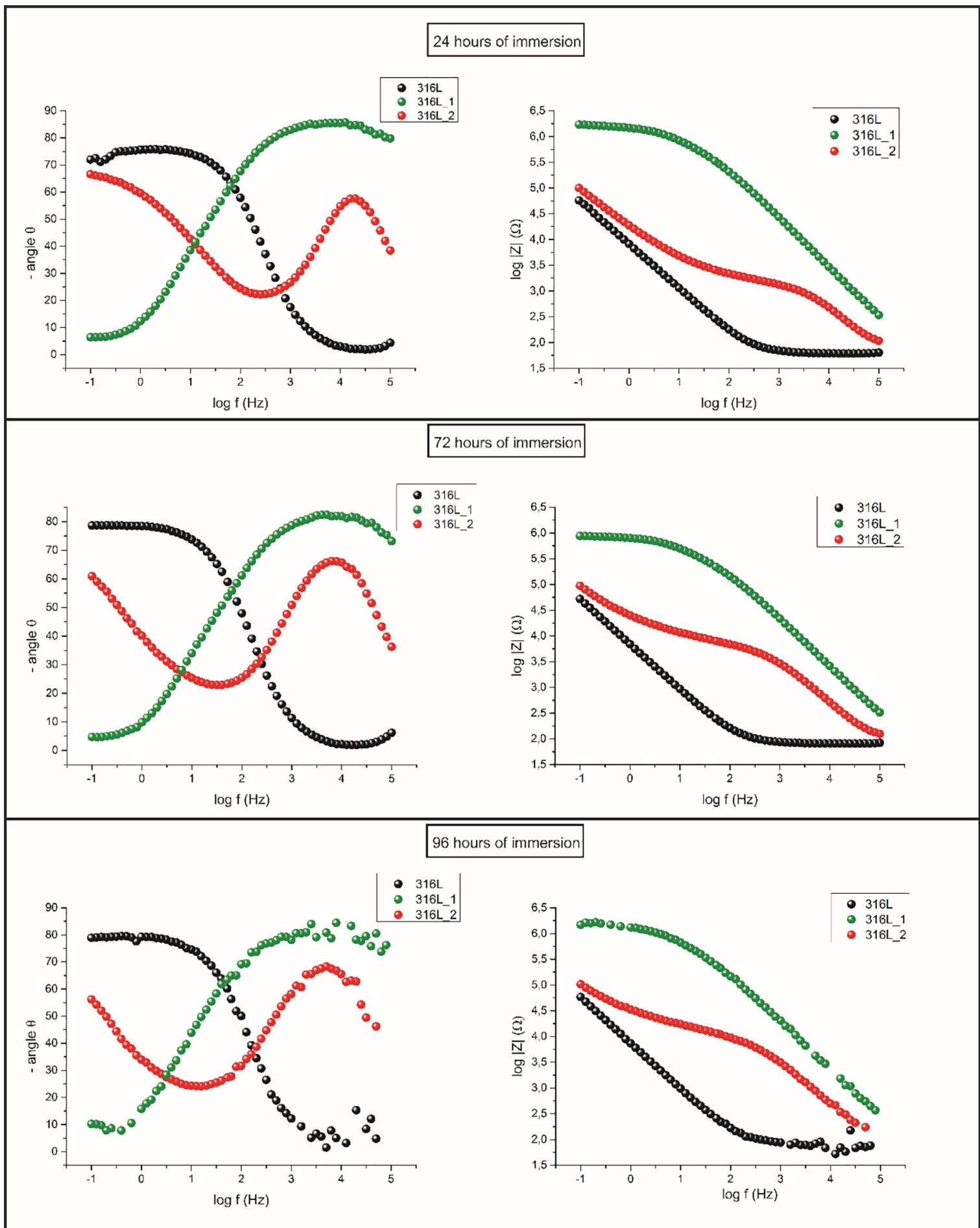

Figure 7. Bode curves of the samples immersed for 24, 72 and 120 hours.

The phase angles for samples with 96 hours of immersion were not as different as the samples with 24 hours of immersion, indicating that part of the siloxane network that adhered to the substrate was still intact. This proves the protective barrier of the film when compared to the passive oxides of the substrate $316 \mathrm{~L}$. The $316 \mathrm{~L} \_1$ sample obtained a subtly inferior angle to $85^{\circ}$. On the other hand, the $316 \mathrm{~L} \_2$ sample presented an angle of $60^{\circ}$ with 24 hours of immersion, and after 96 hours of immersion it presented a higher angle, around $70^{\circ}$.

Figure 8 presents the images obtained through FEG-SEM for the same samples after 96 hours of immersion in EIS. 

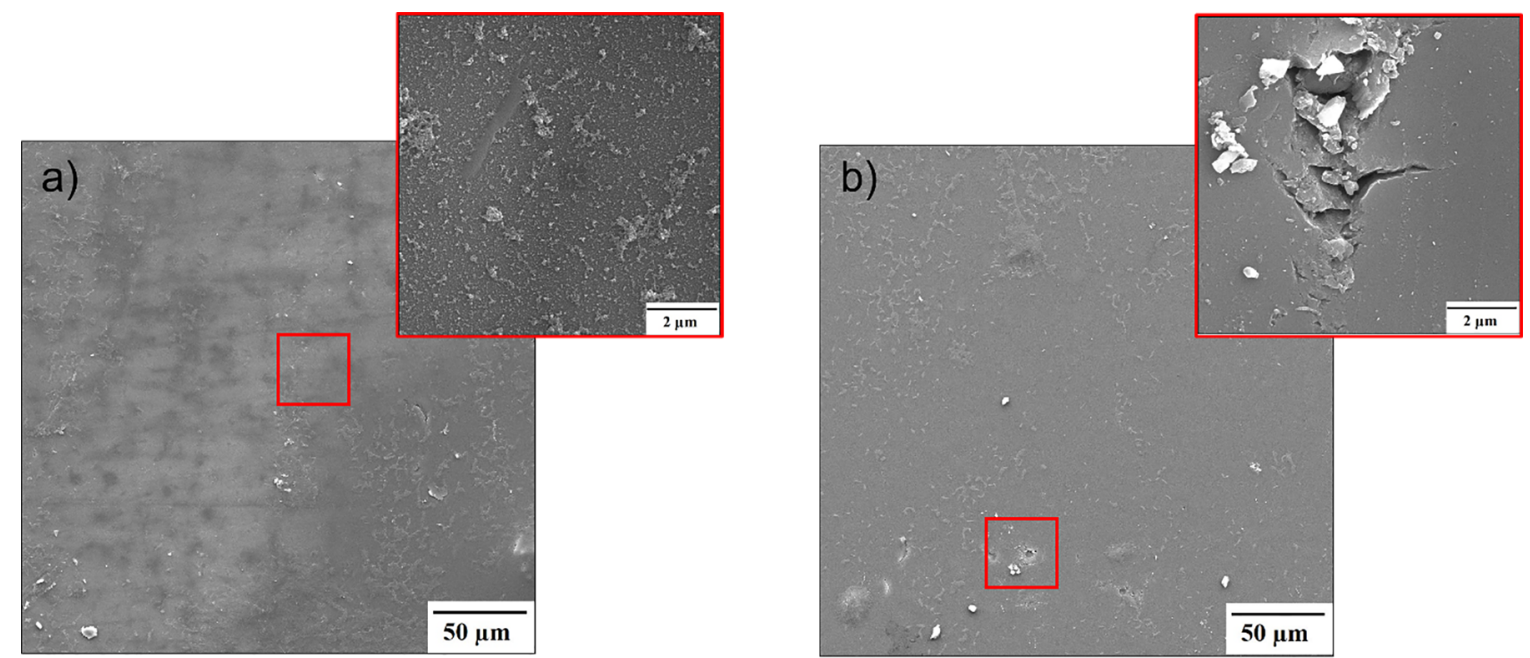

Figure 8. Top micrograph obtained through FEG-SEM for the same samples after 96 hours of immersion in EIS.

The images of Figure 8 were obtained in the area of contact with the electrolyte and the appearance of a crystal layer was observed. This is possibly due to corrosion products such as diffuse oxides surface of the hybrid film coated samples for both samples, for instance, one coating application in 316L_1 and two in 316L_2.

The 316L_2 sample (Figure 8-b) presented more corrosion products than $316 \mathrm{~L} \_1$ sample, demonstrating a higher susceptibility to corrosion, with occasional fissures that can become points of preference for the beginning of concentrated corrosion. One aspect that might have contributed to this result is the more irregular and uneven surface observed in the topographic image of AFM (Figure 5-c), favoring the appearance of clenches in the hybrid film, as observed in detail in Figure 8(b). This reinforces the idea that one of the possible causes for the increase in the current for the 316L_2 sample (Figure 6-b) is the presence of small gaps in the coating.

The 316L_1 sample (Figure 8-a) presents a lower quantity of corrosion products, which supports the good results obtained by the polarization curves (Figure 6-b) to the higher impedance modules according to the Bode plots (Figure 7-b). Results such as the homogenous coating perceived in the micrographs obtained through FEG-SEM (Figure 2-a), good adherence to the substrate (Figure 3-a), uniformity and higher layer thickness (Figure 4-a), and the regular surface observed in the AFM topographic image (Figure 5-b) contributed to the good protective results of this sample.

The 316L_1 sample did not present displacement clenches of the coating after 120 hours of immersion in SBF (Figure 8-a), justifying a more satisfactory result in relation to the $316 \mathrm{~L} \_2$ sample, which shows that this sample is a promising alternative for the protection of biomaterials made of austenitic steel $316 \mathrm{~L}$.

\section{Conclusions}

In this study, the austenitic steel $316 \mathrm{~L}$ was coated with films composed by alkoxide precursors (TEOS-MAP) by using the sol-gel method and the dip-coating process to protect them from the corrosion created by body fluids (SBF).

One application of TEOS-MAP coating showed better performance in electrochemical tests, indicating a higher resistance to corrosion, even after 120 hours of immersion in SBF. This film presented, as shown in the micrographs obtained through FEG-SEM, a regular appearance with no fissures and a hydrophobic character.

Based on the results, it can be concluded that the TEOS-MAP coating is adequate as a protective film for the austenitic steel 316L. The TEOS-MAP film guarantees the protection and integrity of $316 \mathrm{~L}$ in short periods of immersion. Hence, this coating can be a reliable alternative to be used in biomaterials.

\section{Acknowledgements}

The authors express their gratitude to CAPES and CNPq for the financial support, and to the University of Caxias do Sul (UCS) and the Federal University of Rio Grande do Sul (UFRGS) for the equipment used in this study.

\section{References}

1. Pradeep PremKumar K, Duraipandy N, Kiran MS, Rajendran N. Antibacterial effects, biocompatibility and electrochemical behavior of zinc incorporated niobium oxide coating on 316L SS for biomedical applications. Applied Surface Science. 2018;427(Pt B):1166-1181.

2. SuY, Luo C, Zhang Z, Hermawan H, Zhu D, Huang J, et al. Bioinspired surface functionalization of metallic biomaterials. Journal of the Mechanical Behavior of Biomedical Materials. 2018;77:90-105. 
3. Rahman ZU, Deen KM, Cano L, Haider W. The effects of parametric changes in electropolishing process on surface properties of 316L stainless steel. Applied Surface Science. 2017;410:432-444.

4. Brooks EK, Brooks RP, Ehrensberger MT. Effects of simulated inflammation on the corrosion of $316 \mathrm{~L}$ stainless steel. Materials Science and Engineering: C. 2017;71:200-205.

5. Muley SV, Vidvans AN, Chaudhari GP, Udainiya S. An assessment of ultra fine grained 316 L stainless steel for implant applications. Acta Biomaterialia. 2016;30:408-419.

6. Sharifnabi A, Fathi MH, Yekta BE, Hossainalipour M. The structural and bio-corrosion barrier performance of $\mathrm{Mg}$-substituted fluorapatite coating on 316L stainless steel human body implant. Applied Surface Science. 2014;288:331-340.

7. Rezaei B, Havakeshian E, Ensafi AA. Stainless steel modified with an aminosilane layer and gold nanoparticles as a novel disposable substrate for impedimetric immunosensors. Biosensors \& Bioelectronics. 2013;48:61-66.

8. Anghelina FV, Ungureanu DN, Bratu V, Popescu IN, Rusanescu CO. Fine structure analysis of biocompatible ceramic materials based hydroxyapatite and metallic biomaterials 316L. Applied Surface Science. 2013;285(Pt A):65-71.

9. Holzapfel BM, Reichert JC, Schantz JT, Gbureck U, Rackwitz L, Nöth U, et al. How smart do biomaterials need to be? A translational science and clinical point of view. Advanced Drug Delivery Reviews. 2013;65(4):581-603.

10. Nagarajan S, Rajendran N. Surface characterisation and electrochemical behaviour of porous titanium dioxide coated 316L stainless steel for orthopaedic applications. Applied Surface Science. 2009;255(7):39273932.

11. Wang X, Li G, Li A, Zhang Z. Influence of thermal curing on the fabrication and properties of thin organosilane films coated on low carbon steel substrate. Journal of Materials Processing Technology. 2007;186(1-3):259-264.

12. Beltrami LVR, Kunst RS, Birriel EJ, Malfatti CF. Magnetoelastic biosensors: Corrosion protection of an FeNiMoB alloy from alkoxide precursors. Thin Solid Films. 2017;624:83-94.

13. Salvador DG, Marcolin P, Beltrami LVR, Brandalise RN, Kunst SR. Influence of the pretreatment and curing of alkoxysilanes on the protection of the titanium-aluminum-vanadium alloy. Journal of Applied Polymer Science. 2017;134(46):45470.

14. Sarmento VHV, Schiavetto MG, Hammer P, Benedetti AV, Fugivara $\mathrm{CS}$, Suegama PH, et al. Corrosion protection of stainless steel by polysiloxane hybrid coatings prepared using the sol-gel process. Surface and Coatings Technology. 2010;204(16-17):2689-2701 .

15. Owens GJ, Singh RK, Foroutan F, Alqaysi M, Han CM, Mahapatra $\mathrm{C}$, et al. Sol-gel based materials for biomedical applications. Progress in Materials Science. 2016;77:1-79.

16. Child TF, van Ooij WJ. Application of Silane Technology to Prevent Corrosion of Metals and Improve Paint Adhesion. Transactions of the Institute of Metal Finishing. 1999;77(2):6470 .

17. Franquet A, Terryn H, Vereecken JI. IRSE study on effect of thermal curing on the chemistry and thickness of organosilane films coated on aluminium. Applied Surface Science. 2003;211(14):259-269.
18. Teo M, Kim J, Wong PC, Wong KC, Mitchell KAR. Investigation of interfaces formed between bis-1,2-(triethoxysilyl)ethane (BTSE) and aluminum after different Forest Product Laboratory pre-treatment times. Applied Surface Science. 2004;221(1-4):340-348.

19. Casagrande RB, Kunst SR, Beltrami LVR, Aguzzoli C, Brandalise $\mathrm{RN}$, Malfatti CF. Pretreatment effect of the pure titanium surface on hybrid coating adhesion based on tetraethoxysilane and methyltriethoxysilane. Journal of Coatings Technology and Research. 2018;15(5):1089-1106.

20. Sakai RT, da Cruz FMDL, de Melo HG, Benedetti AV, Santilli CV, Suegama PH. Electrochemical study of TEOS, TEOS/MPTS, MPTS/ MMA and TEOS/MPTS/MMA films on tin coated steel in 3.5\% $\mathrm{NaCl}$ solution. Progress in Organic Coatings. 2012;74(2):288-301.

21. Certhoux E, Ansart F, Turq V, Bonino JP, Sobrino JM, Garcia J, et al. New sol-gel formulations to increase the barrier effect of a protective coating against the corrosion of steels. Progress in Organic Coatings. 2013;76(1):165-172.

22. Kunst SR, Ludwig AG, Matos Mandujano JF, Malfatti CF. Influencia del tiempo de hidrólisis en la obtención de película híbrida com adición de íones cerio para la protección de aceros galvanizados. Revista Facultad de Ingeniería Universidad de Antioquia. 2013;69:124-135.

23. Kokubo T, Takadama $\mathrm{H}$. How useful is $\mathrm{SBF}$ in predicting in vivo bone bioactivity? Biomaterials. 2006;27(15):2907-2915.

24. Beltrami LVR, Beltrami M, Roesch-Ely M, Kunst SR, Missell FP, Birriel EJ, et al. Magnetoelastic sensors with hybrid films for bacteria detection in milk. Journal of Food Engineering. 2017;212:18-28.

25. Deflorian F, Rossi S, Fedrizzi L. Silane pre-treatments on copper and aluminium. Electrochimica Acta. 2006;51(27):6097-6103.

26. Longhi M, Kunst SR, Beltrami LVR, Kerstner EK, Silva Filho CI, Sarmento VHV, et al. Effect of Tetraethoxy-silane (TEOS) Amounts on the Corrosion Prevention Properties of Siloxane-PMMA Hybrid Coatings on Galvanized Steel Substrates. Materials Research. 2015;18(6):1140-1155.

27. Assis SL, Rogero SO,Antunes RA, PadilhaAF, Costa I.AComparative study of the in vitro corrosion behavior and cytotoxicity of a superferritic stainless steel, a Ti-13Nb-13Zr alloy, and an austenitic stainless steel in Hank's solution. Journal of Biomedical Materials Research Part B: Applied Biomaterials. 2005;73B(1):109-116.

28. Wolynec S. Técnicas Eletroquímicas em Corrosão. $1^{\mathrm{a}}$ ed. São Paulo: EdUSP; 2003. 166 p.

29. Giordano EJ,Alonso-Falleiros N, Ferreira I, Balancin O. Electrochemical behavior of two austenitic stainless steel biomaterials. REM: Revista Escola de Minas. 2010;63(1):159-166.

30. Pérez C, Collazo A, Izquierdo M, Merino P, Nóvoa XR. Characterization of the barrier properties of different paint systems. Part II. Non-ideal diffusion and water uptake kinetics. Progress in Organic Coatings. 1999;37(3-4):169-177.

31. van Ooij WJ, Zhu D. Eletrochemical Impedance Spectroscopy of Bis-Triethoxysiliypropyl]-Tetrasulfide on Al 2024-T3 Substrates. Corrosion. 2001;57(5):413-427.

32. Romano AP, Fedel M, Deflorian F, Olivier MG. Silane sol-gel film as pretreatment for improvement of barrier properties and filiform corrosion resistance of 6016 aluminium alloy covered by cataphoretic coating. Progress in Organic Coatings. 2011;72(4):695-702. 